\title{
W.H.O. GOITRE TEAM
}

Talks by Prof. Ramalingasprami of the Institute of Medical Sciences, Delhi and Drs. Dev and Karmadkar, members of a team which welt to Trishuli and Jumla in Nepa! to study the etiology of endemic goitre, was arranged at NMA Headquarters building on 8th April '69 by the Scientific and Research Sub-committee. Our President Dr. L. N. Prasad was in the chair.

Assuming that the children of the area were well represented at the school, Prof. Ramalingaswami said that study of incidence of goitre in school children between 13 and 18 years was an accurate method of finding incidence of goitre in an endemic area. They found goitre in about $70 \%$ of school children of this age group in Trishuli and $90-95 \%$ in Jumla. Incidence of nodule formation showed how intensively endemic an area was, and also that the goitre producing factor has acted for a long time in members of the community. In the "study of school children and also in the study of a whole village in Trishuli and Jumla they had found a high incidence of nodule formation. Jumla was probably the most intensely endemic area in the world for goitre. There a good porportion of children ten years of age had nodular goitre.

Dr. Dev who had carried out similar studies in Ceylon, said that Iodine metabolism studies were most important in settling the problem of etiology of endemic goitre, that is whether lodine uptake interfered by noxious agents or whether the goitre was due to deficiency of lodine intake in water and food. Study of I $^{131}$ uptake and urinary excretion of Plasma inorganic iodine (PII) fand PBI were done in endemic areas. In the endemic goitre of the Himalayas iodine uptake was high indicating iodine deficiency as the cause of endemicity. $1^{131}$ uptake at Trishuli was $70-80 \%$ and at Jumla $85-90 \%$. Urinary excretion rate in the Himalayas was only half of that in endemic goitre areas in Ceylon. Because the thyroid by increased activity and - enlargement tries to compensate, PBI is not lowered in mildly endemic areas but there is a limit to the compensation and in severely endemic areas the PBI falls. This was illustrated by the finding of about $4.5 \mathrm{mgm} \%$ PBJ in Ceylon goitres and $2.5 \mathrm{mgm} \%$ (which is below normal limits) in the Himalayas. Also these goitres turned lodine over very quickly so that $\mathrm{I}^{131}$ was almost immediately circulated as PII. The PII values had not been evaluated yet. In Ceylon they had been found 10 be $50 \%$ of normal. Dr. Karmadkar said that ia normal persons the proportion of the hormone secreted by the thyroid as Triiodothyronine $\left(\mathrm{T}^{3}\right)$ (which is 5 times more potent than thyroxine) was very small but in endemic goitre much of the circulating hormone was as $\mathrm{T}^{3}$. The iodine content of $27 \mathrm{~s}$ thyroglobulin was high instead of being the $0.5 \%$ in $19 \mathrm{~s}$ thyroglobulin. Due to lack of human material, studies were carried out on the thyroid of slaughtered goats of endemic areas in North India and it was found that they contained $23 \%$ of such protein instead of $9 \%$ from thyroids, of goats in non-endemic areas. Therefore the gland in endemic areas produces more of the 


\section{W.H.O. GOITRE TEAM}

Talks by .Prof. Ramalingaswami of the Institute of Medical Sciences, Delhi and Drs. Der and Karmadker, members of a team which welt to Trishuli and Jumla in Nepal to study the etiology of endemic goitre, was arranged at NMA Headquarters building on 8th April '69 by the Scientific and Research Sub-committee. Our President Dr. L. N. Prasad was in the chair.

Assuming that the children of the area were well represented at the school, Prof. Ramalingaswami said that study of incidence of goitre in school children between 13 and 18 years was an accurate method. of finding incidence of goitre in an endemic area. They found goitre in about $70 \%$ of school children of this age group in Trishuli and $90-95 \%$ in Jumla. Incidence of nodule formation showed how intensively endemic an area was, and also that the goitre producing factor has acted for a long time in members of the community. In the "study of school children and also in the study of a whole village in Trishuli and Jumla they bad found a high incidence of nodule formation. Jumla was probably the most intensely endemic area in the world for goitre. There a good porportion of children ten years of age had nodular goitre.

Dr. Dev who had carried out similar studies in Ceylon, said that Iodine metabolism studies were most important in settling the problem of etiology of endemic goitre, that is whether lodine uptake interfered by noxious agents or whether the goitre was due to deficiency of lodine intake in water and food. Study of $\mathbf{I}^{\mathbf{1 3 1}}$ uptake and urinary excretion of Plasma inorganic iodine (PII)!and PBI were done in endemic areas. In the endemic goitre of the Himalayas iodine uptake was high indicating iodine deficiency as the cause of endemicity. J $^{131}$ uptake at Trishuli was $70-80 \%$ and at Jumia $85-90 \%$. Urinary excretion rate in the Himalayas was only half of that in endemic goitre areas in Ceylon. Because the thyroid by increased aclivity and enlargement tries to compensate, PBI is not lowered in mildly endemic areas but there is a limit to the compensation and in severely cndemic areas the PBI falls. This was illustrated by the finding of about $4.5 \mathrm{mgm} \%$ PBI in Ceylon goitres and $2.5 \mathrm{mgm} \%$ (which is below normal limits) in the Himalayas. Also these goitres turned Iodine over very quickly so that [131 was almost immediately circulated as PII. The PII values had not been evaluated yet. In Ceyton they had been found 10 be $50 \%$ of normal. Dr. Karmadkar said that in normal persons the proportion of the hormone secreted by the thyroid as Triiodothyronine $\left(\mathrm{T}^{3}\right)$ (which is 5 times more potent than thyroxine) was very small but in endemic goilre much of the circulating hormone was as $\mathrm{T}^{3}$. The iodine content of $27 \mathrm{~s}$ thyroglobulin was high instead of being the $0.5 \%$ in 19 s thyroglobulin. Due to lack of human material, studies were catried out on the thyroid of slaughtered goats of endemic areas in North India and it was found that they contained $23 \%$ of such protein instead of $9 \%$ from thyroids, of goats in non-endemic areas. Therefore the gland in endemic areas produces more of the 
active hormone and more of the protein which contains more hormone. Prof. Swami in his concluding remarks praised Dr Gautam, the Nepali member of the team without whom they could not have carried out the work and hoped that the Department of Health Services will encourage Dr Gautam to form endemic goitre research unit in Nepal. Studies in many endemic areas of the world had shown no gross physical defects due to the goitre in endemic areas; except that in very large goitres the person could not sleep well in the supine position due to pressure on the respiratory passage so that they sleep on the side. Whether the goitre became a cosmetic defect varied with communal social outlook. In a community in an endemic area if the majority had gojtre, a person not having a goitre may be treated by others as being abnormal. Of course for girls with goitre there may be matital difficulties. On the other hand a man with a large goitre did not want it removed because he believed he would continue to earn more money only as long his neck was increasing in size. But there was a high incidence of deaf-mutism, cretinism and hypothyroidism in a severely endemic area-as much as $10 \%$ of the population in Jumla. Could this be due to excessive inbreeding in those communities ? They have particularly looked for defects in iodine metabolism in these cases but did not find cases of congenital metabolic defects.

There was a discussion afterwards in which NMA members took part. In reply to a question Prof. Swami said that Sir Robert Macarrison's observations on pollution of water causing goitre had not been supported by the work of others using the methods of iodine studies which are available now a days. Prof. Swami would have liked to visit the silne areas in Gilgit where Sir Robert had made the studies, for carrying out research 1 ith modern means.

There were hardly any cases of Hashimoto's in endemic goitress. He did not see any case of Hashimoto's in Trisuli and Jumla. May be endemic goitre protected them from the auto immune thyroiditis.

He did not believe there was any increased incidence of malignancy in endẹnic goicre. Unlike the figures of upto $25 \%$ in European races, in endemic goitre areas the solitary cold nodules would be due to necrosis of the benign modulue

Prof. Swami said that in his experience there was no such thing as thyrotoxicrsis developing in multinodular goitres in endemic areas. A questioner pointed out that this was not the experience in the West. Prof. Swami said that the cause of goitre in certain endemic foci in Great Britain was not known therefore his statement did not apply to the West. Iatrogenic thyrotoxicoses in endemic areas could be caused by giving excessive amount of jodine to cases of multinodular goitre. A gland working hard to maintain a euthyroid state (and many endemic goitres were Euthyroid) if suddenly flooded by iodine produces excessive thyroid hormone (Jod-Basedow's disease). The questioner pointed out that the practice of giving Mist goitre containing Iodides as treatment of goitres in adults may do just that without helping the goitre at all.

In reply to a question Prof. Swami stated that the salt being supplied by India 10 . Nepal has one aprt of Potassium iodate mixed with. 40000 parts of common salt. This 
should help the future generation of Nepalese from developing goitre but in the desp interior salt came from Tibet which was not iodinated.

Dr. L. N. Prasad mentioned that about 75 cases of deafmutism had been found at Dhulikhel which had a population of 4000 and did not have any appreciable incidence of goitre but had been almost totally inbred bocause wherever they warked or lived, Dhulikhel people always came back to their village to get married. Therefore a detailed study of the village may show whether inbreeding also could not be responsible for deafmutism in Nepal.

After the talk a film on Fucidin by Leo Pharmaceuticals and a film of tourist interest on Denmark were shown. These films shows as well as tea and snacks were arranged by Mr. Ram Krishna Shrestha of Kathmendu Medical Hall.

\section{JNMA Will be pleased}

[1010 [D(1)
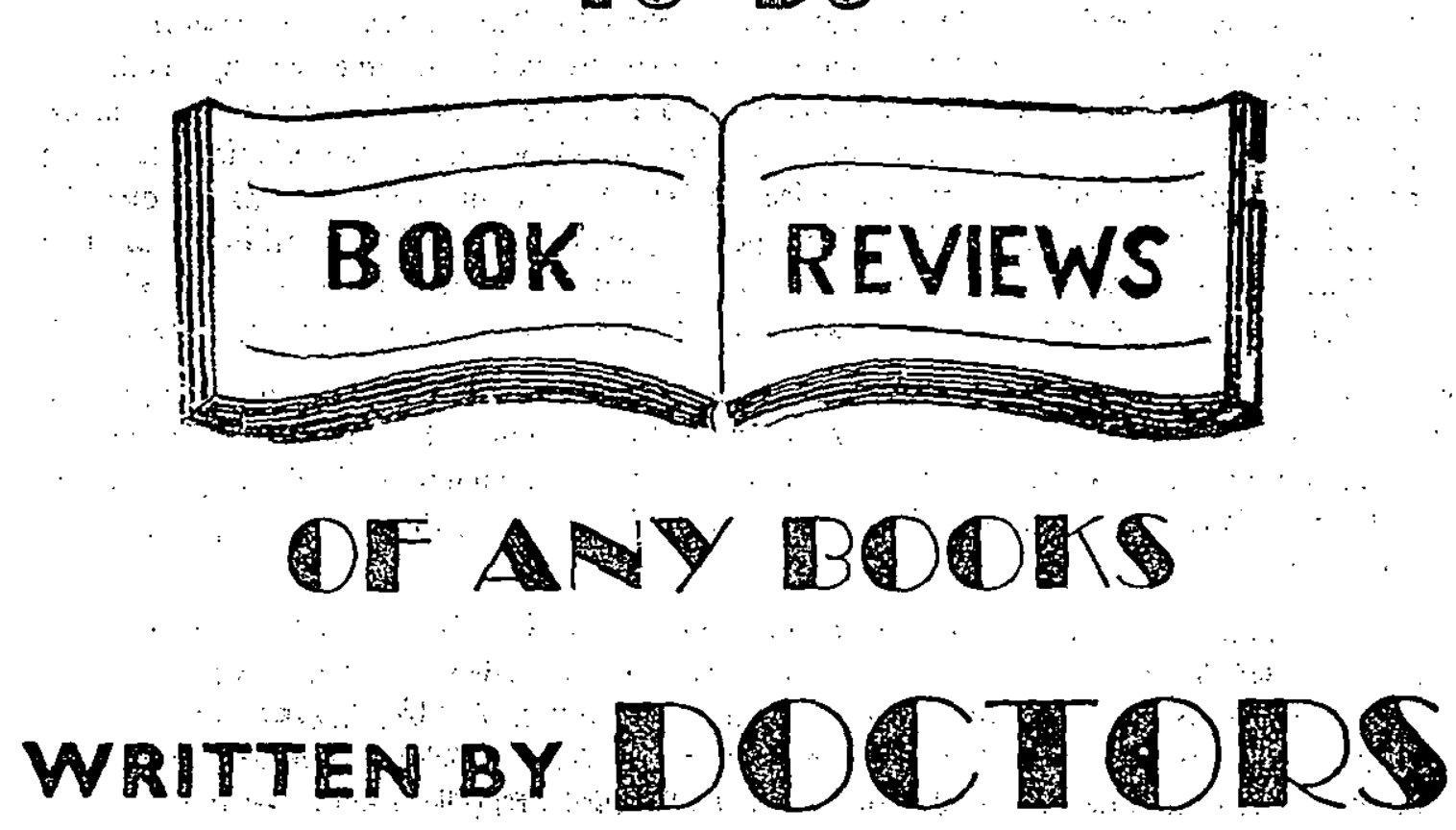